\title{
Refractory Liver Carcinoma
}

National Cancer Institute

\section{Source}

National Cancer Institute. Refractory Liver Carcinoma. NCI Thesaurus. Code C153352.

Liver carcinoma that is resistant to treatment. 